\title{
Occurrence of Ocular Fundal Changes in Cases of Infective Meningitis and Meningoencephalitis in Our Hospital
}

\author{
Dr Sanjay Pachapure ${ }^{1}$, Dr Mahesh B S ${ }^{2}$, Dr Myna T Achar ${ }^{3}$ \\ ${ }^{1}$ (Ophthalmology Department, JSS Medical College, India) \\ ${ }_{2}^{2}$ (Ophthalmology Department, JSS Medical College, India) \\ ${ }^{3}$ (Ophthalmology Department, JSS Medical College, India)
}

\begin{abstract}
Background and objective: Central Nervous System (CNS) infections are known to cause papilloedema and retinal changes. Direct fundoscopy is an established aspect of neurological examination and serve as a direct reflection of different pathologies occurring in the brain. In this study we aim to study the occurrence of disc and retinal changes in cases with infective meningitis and meningo-encephalitis.

Methods: A prospective study was done from October 2011 to June 2013 in patients above 6 years of age with clinical diagnosis of infective meningitis or meningo-encephalitis.

Results: A total of 57 cases of meningitis/meningo-encephalitis were studied. Mean age in our study group was 28.84 years. Out of 57 patients, 30 (52.6\%) were male and 27 (47.4\%) were female patients. Oculovisual anomalies were seen in $20(35.1 \%)$ patients. The ocular abnormalities included cranial nerve palsy $4(7 \%)$ and fundus changes $18(31.6 \%)$. All 4 (7\%) cases with cranial nerve palsy had $6^{\text {th }}$ cranial nerve involvement. Fundal changes included papilloedema 19 (33.3\%), hyperemia 19 (33.3\%) and haemorrhage $3(5.3 \%)$.

Discussion: Meningitis is the most common CNS disease affecting both children and adults leading to focal neurological deficits and various oculovisual anomalies including blindness in children. Ocular abnormalities form an important group of clinical manifestations of meningitis.
\end{abstract}

Keywords: Meningitis, meningo-encephalitis, oculovisual anomalies

\section{Introduction}

Meningitis is the most common central nervous system disease affecting children ${ }^{1}$ leading to focal neurological deficits and various oculovisual anomalies including blindness in children. ${ }^{2}$

The meningitis/meningo-encephalitis may be caused by infection with viruses, bacteria, other microorganisms, or non-infective causes.

Bacterial meningitis remains a common disease worldwide. The incidence of bacterial meningitis is between 3 and 5 per 100,000 people per year and more than 2,000 deaths are reported annually in the United States. The disease is even more common in developing countries. ${ }^{3}$ The community incidence of acute bacterial meningitis in India is not known. ${ }^{4}$

Nearly all cases of $\mathrm{H}$. influenzae meningitis occur in children under 6 years of age. Pneumococcal meningitis is the most common type of meningitis in adults over the age of $30 .^{3}$

Commonly seen meningitis in children is of two types-Pyogenic and Tubercular. Both these types of meningitis can be associated with cranial neuropathies of II, III, IV, VI and VII cranial nerves due to focal or generalized inflammation. ${ }^{2}$

Optic neuritis, optic atrophy and papilloedema are the most important neurological sequelae of meningitis, mainly, tubercular. Meningitis may also be associated with lid retraction, gaze paresis, squint, tonic deviation of eyes, nystagmus, pupillary abnormality in size and reaction, panophthalmitis and exposure keratitis.

According to the WHO meeting on childhood blindness in 1990 there are approximately 1.5 million blind children in the world of which $90 \%$ live in the developing countries. ${ }^{5}$ Choroidal tubercles and papilloedema were found to be signs of grave prognostic significance. Thus, meningitis is an important cause of mortality and morbidity in the form of neurological sequelae and remains a serious global health problem in spite of potent antibiotics and improved treatment modalities.

Central Nervous System (CNS) infections are known to cause papilloedema and retinal changes. Aetiopathogenesis and clinical features of papilloedema have been studied extensively. Not much work has been done on retinal changes in CNS infections. In our study we aim to study the occurrence of disc and retinal changes in cases with infective meningitis and meningo-encephalitis. 


\section{Review of the Literature}

Meningitis is an infection predominantly involving meninges. Whereas meningoencephalitis is involvement of meninges along with the brain parenchyma. Nuchal rigidity (stiff neck): pathognomonic sign of meningeal irritation. Clinical triad of meningitis is fever, headache \& nuchal rigidity. Decreased level of consciousness can vary from lethargy to coma.

Raised Intracranial pressure (ICP) can give rise to many ocular manifestations like papilledema, relative afferent papillary defect and cranial nerve palsies.

Annual Incidence of meningitis in united state is $>2.5 \mathrm{cases} / 1,00,000$ population. ${ }^{12}$ Annual incidence of Bacterial meningitis in India is 4-6 cases/1,00,000adults. ${ }^{13}$ Organism most commonly responsible for community acquired bacterial meningitis are: Streptococcus pneumoniae $50 \%$; Neisseria meningitides $25 \%$; group B streptococci 15\%; Listeria meningitidis $10 \%$. In the recent times many viral and other infections are also recognized to have signs of meningeal irritation and encephalitis.

\section{Pathogenesis}

Inflammatory cytokines promote leukocyte adherence to vascular endothelial cells \& subsequent migration into the Cerebrospinal Fluid (CSF). This increases permeability of blood vessels, leakage of plasma protein into the CSF, which adds to inflammatory exudates.

Sub-arachnoid exudates of proteinaceous material \& leukocytes obstructs the flow of CSF through the ventricular system \& diminishes the resorptive capacity of the arachnoid granulations in the dural sinuses, leading to obstructive \& communicating hydrocephalus \& concomitant interstitial edema.

Narrowing of large arteries at the base of the brain due to encroachment by purulent exudate in the subarachniod space \& infiltration of wall by inflammatory cells with intimal thickening (vasculitis), results in ischaemia \& infarction.

Combination of interstitial; vasogenic \& cytotoxic edema leads to raised intracranial pressure \& coma. We postulate that similar changes may occur in the retina as it is a close extension of the CNS.

Laktaoui et al reported association of macular tuberculoma and optic neuritis with tubercular meningoencephalitis, ocular fundus demonstrating a yellow tumor measuring $1.5-2 \mathrm{~mm}$, papillomatous and prominent in the vitreous cavity. Flourescein angiography showed a peritumoral choroiditis area, miliary tubercles of the choroid and sectorial papillomatous edema. ${ }^{14}$

Chotmongkol et al reported bilateral papilloedema in benign form of herpes simplex encephalitis. ${ }^{15}$ Tahir $\mathrm{M}$ et al reported bilateral papilloedema in a case of dengue-3 virus infection. ${ }^{16}$ Johnson BL, Wisotzkey HM reported disc and retinal changes associated with herpes simplex encephalitis in an adult patient. ${ }^{17}$ Yuksel $\mathrm{D}$ et al reported chorioretinitis in subacute sclerosing panencephalitis. ${ }^{18}$ John J.Piel M.D et al reported bilateral papilloedema ina case of encephalitis caused by Infectious mononucleosis. ${ }^{19}$ Wang IJ et al reported papilloedema in a case of acute encephalitis. ${ }^{20}$ Yukiko Tada et al reported characteristic scattered yellowishwhite retinal exudates, retinal hemorrhage, retinal vasculitis and edema of the optic disc in a case of herpes simplex meningitis. ${ }^{21}$

Chan CK et al reported multifocal chorioretinal target lesions (85.7\%),retinal hemorrhages (50.0\%), chorioretinal linear streaks (28.6\%), optic atrophy (14.3\%), vascular occlusion in eye (14.3\%) and facial nerve palsy $(7.1 \%)$ in cases of west nile fever. ${ }^{22}$

Khairallah $\mathrm{M}$ et al reported white retinal lesions (30\%), intraretinal hemorrhage (23.3\%), white centered retinal hemorrhage (3.3\%), sub-retinal hemorrhage (3.3\%), serous retinal detachment (5\%), macular star (3.3\%), cystoid macular edema (1.7\%), optic disc edema (1.7\%) in cases of rickettsia conorii infection. ${ }^{23}$

Incidences of retinal changes in cases of infective diseases with CNS involvement have not been studied in our population to the best of our knowledge.

\section{Source of data:}

\section{Materials And Methods}

All patients with clinical diagnosis of meningitis or meningo-encephalitis in JSS Hospital, Mysore who fulfill the conditions of the following inclusion and exclusion criteria.

Type of study: Prospective study.

Period of Study: October 2011 to June 2013

Inclusion criteria: All patients above 6 years of age with clinical diagnosis of infective meningitis or meningoencephalitis.

\section{Exclusion criteria:}

- Patients with associated diabetic retinopathy, hypertensive retinopathy, age related macular degeneration or other macular pathology.

- Patients less than 6 years of age.

- Media haze due to anterior segment pathology, lenticular changes or vitreous hemorrhage. 
- Patients with history of trauma, previous retinal surgery, glaucomatous or other causes of optic atrophy.

- Patient with associated Human Immunodeficiency Virus (HIV) infection.

- Non-infective causes of meningitis or meningo-encephalitis.

- Patients who don’t give informed consent for examination.

Consent: Informed consent of parents was taken after explaining in detail about methods and procedures involved in the study in their own vernacular language.

Ethical clearance: Ethical clearance was obtained from the institution.

\section{Method of Collection of data:}

Sample size and method: Purposive sampling technique. We aim to study all clinically diagnosed cases of meningitis or meningo-encephalitis, selected according to the conditions of inclusion and exclusion criteria during the period of study.

\section{Procedure:}

Cases shall be selected according to the conditions of the inclusion and exclusion criteria. The selected cases will then undergo detailed direct and indirect ophthalmoscopic examination and extraocular movement examination. The patients will also undergo visual acuity assessment, a detailed slit lamp evaluation, tonometry by Perkin's applanation tonometer and fundus with slit lamp 90 diopter lens evaluation and fundus photography. If the patient is too sick, preliminary bed side evaluation is done and when the patient is fit or prior to discharge, detailed investigative evaluation is performed.

Selected bedridden patient will be photographed by a Wide-Field Portable Digital Retinal Camera, after instillation of a Local Anaesthetic (Proparacaine 0.5\%).

\section{Statistical methods:}

- Descriptive statistics.

- Frequencies/percentages.

- Contingency co-efficient test

- $\mathrm{X}^{2}$ test

- Statistical operations are done using SPSS (statistical presentation system software) for windows or epi-info

\section{Results}

Mean age in our study group was 28.84 years. We had 30 (52.6\%) male and 27 (47.4\%) female patients. Right eye extra ocular movements were abnormal in $2(3.5 \%)$ patients, which were lateral rectus palsy. This was statistically significant $(\chi 2=49.281, \mathrm{p}=0.001)$. Left eye extra ocular movements were abnormal in 4 (7\%) patients, which were lateral rectus palsy. This was statistically significant $(\chi 2=42.123, \mathrm{p}=0.001)$.

Haemorrhage was observed in the right eye in $2(3.5 \%)$ patients. Haemorrhage was observed in the left eye in $3(5.3 \%)$ patients.

Disc edema was present in $19(33.3 \%)$ and absent in $38(66.7 \%)$ patients. This was statistically significant $(\chi 2=6.333, \mathrm{p}=0.012)$.

Table 1

\begin{tabular}{|c|c|c|}
\hline Disc edema & Frequency & Percentage \\
\hline Absent & 38 & 66.7 \\
\hline Present & 19 & 33.3 \\
\hline Total & 57 & 100 \\
\hline
\end{tabular}


Figure 1

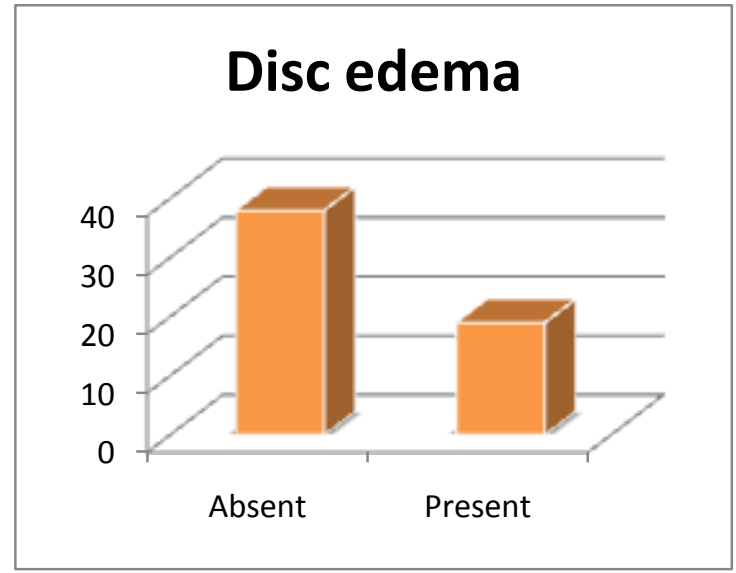

Figure 2 Fundal picture showing papilloedema

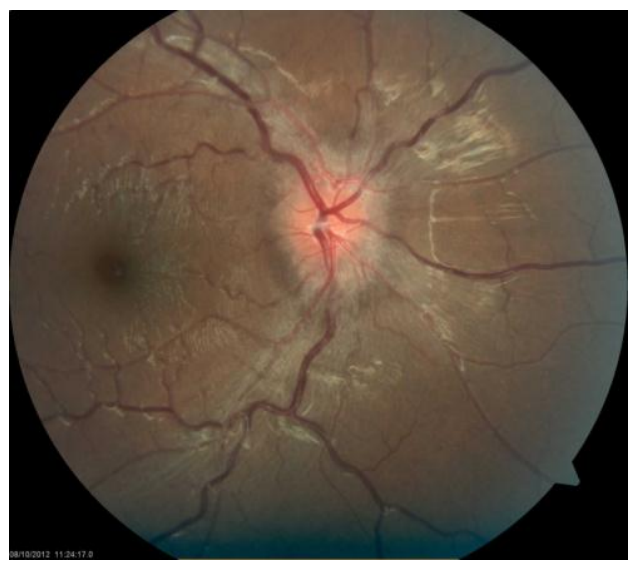

Figure 3 Fundus showing papilloedema with disc haemorrhage

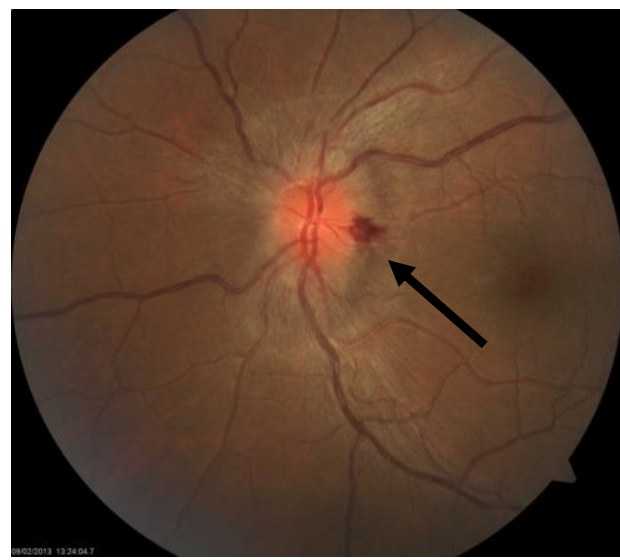

VI. Discussion

Our study included patients from age group of 7 to 70 years. Out of total 57 patients, 19 (33.3\%) were below 20 years and $38(66.7 \%)$ were above 20 years.

\begin{tabular}{|c|c|c|c|c|}
\hline $\begin{array}{c}\text { Present study } \\
(\mathrm{n}=57)\end{array}$ & $\begin{array}{c}\text { Chaudhary M } \\
\text { et al study }(\mathrm{n}=182)\end{array}$ & Lamba PA et al & $\begin{array}{c}\text { Shakuntala } \\
\text { Saxena et al }\end{array}$ & Mooney AJ \\
\hline $20(35.1 \%)$ & $70(38.46 \%)$ & $72.9 \%$ & $89 \%$ & $72 \%$ \\
\hline
\end{tabular}

Table 2: Incidence of oculovisual anomalies in meningitis cases

Present study reveals that 20 (35.1\%) patients had oculovisual anomalies. Chaudhary M et al reported $38.46 \%$ oculovisual anomalies. ${ }^{2}$ Similarly Lamba PA et al ${ }^{24}$ and Shakuntala Saxena et $\mathrm{al}^{50}$ reported $^{2} .9 \%$ and $89 \%$ of oculovisual anomalies respectively. A study done by Alan J. Mooney showed $72 \%$ patients with oculovisual anomalies. ${ }^{51}$ 


\begin{tabular}{|c|c|c|}
\hline Ocular abnormalities & $\begin{array}{c}\text { Present study } \\
(\mathrm{n}=57)\end{array}$ & $\begin{array}{c}\text { Chaudhary M et al study } \\
(\mathrm{n}=182)\end{array}$ \\
\hline Pupillary changes & 0 & 24 \\
\hline Cranial nerve palsy & 4 & 16 \\
\hline Proptosis & 0 & 1 \\
\hline Panophthalmitis & 0 & 25 \\
\hline Fundus changes & 19 & 3 \\
\hline Cortical blindness & 0 & $70(38.46 \%)$ \\
\hline Total & $20(35.1) \%$ & \\
\hline
\end{tabular}

Table 3: Pattern of different ocular abnormalities noted in meningitis cases

In the present study, cranial nerve palsy was observed in $4(7 \%)$ patients. Out of them, 3 patients also had fundal changes. Fundal changes were noted in 19 (33.3\%) patients. Fundal changes were in the form of disc edema and haemorrhage. Haemorrhage was noted in total $3(5.3 \%)$ patients. Chaudhary $\mathrm{M}$ et al study, cranial nerve palsy was noted in 16 patients. Fundus changes were noted in 25 cases. $^{2}$

\begin{tabular}{|c|c|c|}
\hline Type of cranial nerve palsy & Present study & Chaudhary M et al study \\
\hline $3^{\text {rd }}$ nerve palsy & 0 & $12(17.14 \%)$ \\
\hline $6^{\text {th }}$ nerve palsy & $4(7 \%)$ & $3(4.29 \%)$ \\
\hline $3^{\text {rd }}+4^{\text {th }}+6^{\text {th }}$ nerve palsy & 0 & $1(1.43 \%)$ \\
\hline
\end{tabular}

Table 4: Involvement of different cranial nerves in meningitis cases:

Above table shows that $6^{\text {th }}$ nerve palsy was noted in $4(7 \%)$ patients. Chaudhary $\mathrm{M}$ et al study noted higher incidence of $3^{\text {rd }}$ nerve palsy $12(17.14 \%) .^{2}$

Figur 4 Right eye lateral rectus palsy

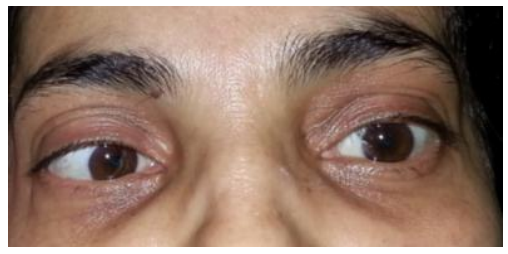

\section{CONCLUSION}

CNS infections are known to cause papilloedema and retinal changes.

Out of 57 cases of meningitis/meningoencephalitis, 30 (52.6\%) were males and $27(47.4 \%)$ were females.

Papilloedema was noted in $19(33.3 \%)$ patients. This was statistically significant $(\chi 2=6.333, \mathrm{p}=0.012)$.

\section{Acknowledgements}

I sincerely thank Dr. MAHESH B. S., Professor and HOD of Ophthalmology for guidance and support throughout my study. I offer my sincere thanks and heartfelt gratitude to my respected guide Dr. MAHESH B. S., Professor \& HOD of Ophthalmology, for providing me valuable help, guidance and encouragement throughout this study.

I also place on record the gratitude to Dr. Rajendra R., Dr. Premnath Raman, Dr. S. K. Prabhakar, Dr. Myna T Achar, Dr. Mangala M. N., Dr. Shanthamalllappa, Dr. Anita T., Dr. Sowmya H. V., Dr. Mahalakshmi of the Department of Ophthalmology, for their valuable support and guidance during this study. I am thankful to my friends Dr. Pulkit Gupta, Dr. Bindhu, Dr. Ajay B. S., Dr. Kruthika, Dr. Priyanka, Dr. Rohit, Dr. Naveen, Dr. Shashidhar, Dr. Prardhana and Dr. Mehak for their help towards completing this study.

I express my most sincere regards and gratitude to my wife, Dr. Shaila and my family members for being a constant source of support. I also thank Mr. Lancy D' Souza for the statistical work and Mr. Selva for the Printing work.

Last but not the least my heartfull thanks to all the patients without whom, this work would not have been possible. Above all I thank almighty. 


\section{REFERENCES}

[1]. Marlene L.Durand.Systemic Infections and the Eye; Albert and Jokobiec's Priciples and Practice of Ophthalmology; $3^{\text {rd }}$ ed;USA;2008;4665-70.

[2]. Meyers SM:The incidence of fundus lesions in septicemia.Am J ophthalmol 1979;88:661-667.

[3]. Neudorfer M,Barnea Y,Geyer O,et al:Retinal lesions in septicemia. Am J Ophthalmol 1993;116:728-734

[4]. Biswas J,Badrinath SS:Ocular morbidity in patients with active systemic tuberculosis.Int Ophthalmol 1967;64:742-748.

[5]. R.Paul Johnson.Systemic Viral Infection and the Eye; Albert and Jokobiec's Priciples and Practice of Ophthalmology; $3^{\text {rd }}$ ed;USA;2008;4687

[6]. Pepose JS,Holland GN,Nestor MS, et al:Aquired immune deficiency syndrome:pathogenic mechanisms of ocular disease.Ophthalmology 1985;92:472.

[7]. Rathinam SR:Ocular manifestation of leptospirosis.J Postgrad Med 2005;51:189-194.

[8]. Forster DJ,Dugel PU,Frangieh GT,et al:Rapidly progressive outer retinal necrosis in the acquired immunodegiciency syndrome.Am J ophthalmol 1990;110:341.

[9]. Parson RJ,Zarafonitis CJD:Histoplasmosis in man:report of 7 cases and a review of 71 cases.Arch Intern Med 1945;75:1.

[10]. Poungvarin N,Praditsuwan R:Opsoclonus in Malaria:the first report in the literature.J Med Assoc Thai 1990;73:462-466.

[11]. Topilow HW,Yimoyines DJ,Freeman HM,et al:Bilateral multifocal intraocular cysticercosis. Ophthalmology 1981;88:1166-1172.

[12]. Karen L.Roos,Kenneth L.Tyler.Meningitis,Encephalitis,Brain abscess and Empyema;Harrison's Principles of Internal Medicine; $17^{\text {th }}$ ed;USA;2008;2621.

[13]. Garg RavindraKumar.Pyogenic Infections of The Central Nervous System;API textbook of Medicine; $8^{\text {th }}$ ed;India;2009;1168.

[14]. Laktaoui A et al:Macular tuberculoma and optic neuritis: rare association with tuberculosis meningoencephalitis.J Fr Ophthamol 2009;32(9):673-8.

[15]. Chotmongkol V,Chimsuk U,Chuesakoolvanich K:Benign form of herpes simplex encephalitis.Southeast Asian J Trop Med Public Health 2003;34(2):393-4.

[16]. Tahir $M$ et al:Dengue fever with papilledema: a case of dengue-3 virus infection in central nervous system.J Clin Virol 2006;37(1):65-7.

[17]. Johnson BL,Wisotzkey HM:Neuroretinitis associated with herpes simplex encephalitis in an adult.Am J Ophthamol 1977;83(4):481-9.

[18]. Yuksel D,Sonmez PA,Yilmaz D,Senbil N,Gurer Y:Ocular findings in subscute sclerosing panencephalitis.Ocul Immunol Inflamm $2011 ; 19(2): 135-8$.

[19]. John J.Piel M.D.,H.E.Thelander M.D.,Edward B.Shaw M.D:Infectious mononucleosis of the central nervous system with bilateral papilledema.Journal of Paediatrics 1950;37(4):661-665.

[20]. Wang IJ et al:The correlation between neurological evaluations and neurological outcome in acute encephalitis:a hospital-based study.Eur J paediatr Neurol 2007;11(2):63-9.

[21]. Yukiko Tada et al:Findings in a patient with Herpes Simplex Viral Meningitis Associated with Acute Retinal Necrosis Syndrome.AJNR Am J Neuroradiol 2001;22:1300-1302.

[22]. Chan CK,Limstrom Sa,Tarasewicz DG,Lin SG:Ocular features of west nile virus infection in North America: a study of 14 eyes. Ophthalmology 2006;113(9):1539-46.

[23]. Khairallah M et al:Posterior segment manifestations of Rickettsial conorii infection. Ophthalmology 2004;111(3):529-34 